\title{
DERMATOMIOZITA JUVENILĂ
}

\author{
Sigrid Covaci, ${ }^{1,2}$, Oana-Maria Farkaş ${ }^{2}$, Alexis-Virgil Cochino ${ }^{1,2}$ \\ ${ }^{1}$ Universitatea de Medicină şi Farmacie „, Carol Davila“", Bucureşti \\ ${ }^{2}$ Institutul Național pentru Sănătatea Mamei şi Copilului „Alessandrescu-Rusescu“, \\ Bucureşti
}

\begin{abstract}
REZUMAT
Dermatomiozita juvenilă este o boală autoimună, cu afectare multisistemică, de origine incertă, la baza căreia se află inflamația perivasculară cronică, şi care afectează în principal țesuturile cutanat şi muscular. Prezentăm cazul unei paciente cu afectarea tegumentară clasică descrisă în dermatomiozită, şi care a dezvoltat afectare musculară la peste un an de la debutul bolii.
\end{abstract}

Cuvinte cheie: dermatomiozită juvenilă, dermatomyositis sine myositis, slăbiciune musculară, miozită, rash heliotrop, semn Gottron

\section{INTRODUCERE}

Bolile imunologice pediatrice, deşi un subiect „la modă“ în mediile de socializare on-line, sunt deseori diagnosticate tardiv, fiind sursa unor complicații/sechele evitabile. Una dintre cele mai frecvent întâlnite, dermatomiozita juvenilă (DMJ), poate să prezinte de la formele cele mai simple şi uşoare (de tipul dermatomiozitei fără miozită), trecând prin cele clasice (afectare cutanată şi musculară), şi până la forme grave, cu potențial letal (cu complicații neurologice, hematologice). Din cauza lipsei unui test cu rol de standard de aur, diagnosticul se stabileşte pe baza unui set de criterii (Bohan şi Peter):

1. Slăbiciune musculară proximală simetrică: musculatura centurilor - pelvină şi scapulară;

2. Creșterea enzimelor de origine musculară: $\mathrm{CK}, \mathrm{LDH}, \mathrm{AST}$, aldolază;

3. Modificări electromiografice (EMG): potențiale polifazice scurte, de mică amplitudine ale unităţii motorii, fibrilații spontane, activitate inserțională, descărcări de complexe înalte, bizare, repetitive;

4. Modificări la biopsia musculară: infiltrat inflamator, frecvent perivascular, cu necroze miofibrilare, atrofie perifasciculară;

5. Manifestări cutanate: rash heliotrop, papule eritematoase (papule Gottron) la nivelul suprafețelor extensoare ale articulațiilor metacarpofalangiene (MCF), interfalangiene proximale (IFP), coate şi genunchi.

Pentru diagnosticul de DMJ este obligatorie prezența manifestărilor cutanate şi a încă 3 criterii (diagnostic cert), 2 criterii (diagnostic probabil) sau 1 criteriu (diagnostic posibil).

Debutul bolii este în general insidios, cu semne generale (iritabilitate, oboseală uşoară, subfebră/ febră, anorexie, pierdere în greutate) care pot preceda diagnosticul cu 3-6 luni (1). Afectarea cutanată poate fi prima manifestare a bolii (precedând cu luni - ani apariția afectării musculare). Nu există o corelație între gradul afectării cutanate şi cel al afectării musculare (2). Leziunile caracteristice constau în rash-ul heliotrop (culoare violacee periorbitar care poate fi însoțită de edem al pleoapelor) şi papule/semne Gottron (papule eritematoase la nivelul suprafețelor extensoare ale MCF, IFP, coate, genunchi, maleolă externă). Alt semn cutanat, mai puțin caracteristic, este erupția facială cu distribuție malară. Uneori se pot observa modificări periunghiale - pat unghial hiperemic prin dilatarea anselor capilare (care uneori pot fi observate cu ochiul liber) sau cuticule zdrențuite (3). Afectarea musculară este simetrică şi predomină la nivelul centurilor, mai ales a celei pelviene (4). Este posibilă afectarea musculaturii flexoare a gâtului, precum şi a celei abdominale. Manifestările viscerale 
(gastro-intesinale, pulmonare, cardiace) semnifică evoluția severă a bolii. O atenție deosebită trebuie acordată apariției disfagiei (care poate sugera hipomotilitatea esofagiană), disfoniei şi vocii nazonate.

Autoanticorpii specifici/asociați miozitei nu sunt necesari pentru diagnostic, dar pot fi utili în definirea subtipurilor de boală şi pot avea rol prognostic.

Se prezintă un caz de DMJ, care a acoperit în evoluție jumătate din spectrul posibil al bolii, de la dermatomiozită fără miozită, până la DMJ formă completă.

\section{PREZENTAREA CAZULUI}

Pacientă în vârstă de 3 ani şi 1 lună se prezintă în INSMC în ianuarie 2014 pentru precizare de diagnostic, cu antecedente personale şi familiale nesemnificative. Debutul bolii a fost în aprilie 2013, cu erupție eritematoasă la nivelul feței (care respecta fruntea şi zona perioronazală), după expunere la soare (aproximativ 2 ore); restul zonelor expuse la soare (mâini) nefiind afectate. Într-un serviciu de dermatologie se stabileşte diagnosticul de alergodermie/arsură solară și se recomandă tratament antihistaminic şi protecție solară. Erupția persistă însă pe parcursul verii, cu perioade de atenuare/accentuare (în special după expunerea la soare) şi cu apariția de elemente noi, eritematoase, la nivelul coatelor, genunchilor, IFP, MCF şi regiunii cervicale posterioare, pentru care primeşte doar tratament antialergic, fără efect. Primele investigații de la debutul bolii (15 octombrie 2013) au fost în limite normale (hemogramă, transaminaze, VSH), cu excepția unei anemii uşoare (Hgb 9,4 g/dl). Până la prezentarea inițială în INSMC nu a prezentat niciodată slăbiciune musculară, scădere în greutate, disfonie, disfagie sau dispnee.

Elementele clinice semnificative la primul consult au fost:

- erupția facială cu respectarea frunții şi a zonei perioronazale (Fig. 1);

- hiperemia pavilionului auricular bilateral (Fig. 1);

- semne Gottron (Fig. 2, 3, 4);

- eritem liniar la nivelul suprafețelor extensoare ale policelui bilateral;

- suflu sistolic gr. II-III/VI;

- fără disfagie/disfonie; forța musculară normală (,se joacă, merge cu bicicleta, urcă şi coboară scările, la fel cu ceilalți copii“");

- manevra Gowers negativă;

- fără dureri abdominale, melenă sau hematemeză.

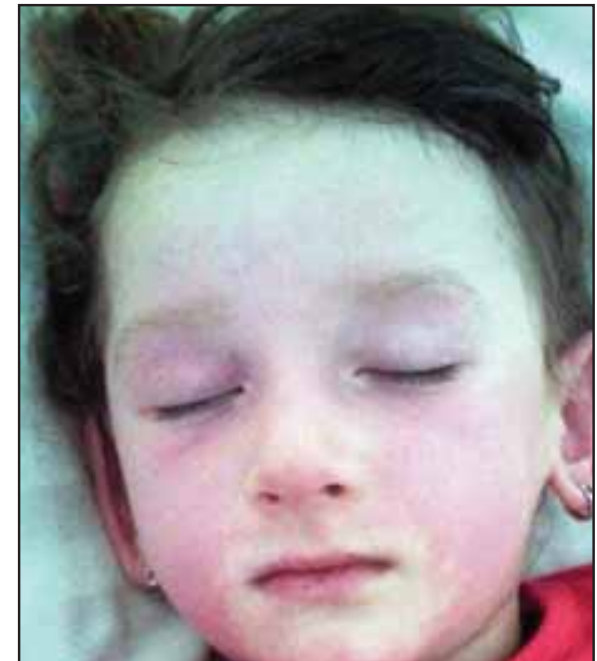

FIGURA 1. Erupție facială cu respectarea frunții şi a zonei perioronazale (distribuție malară)

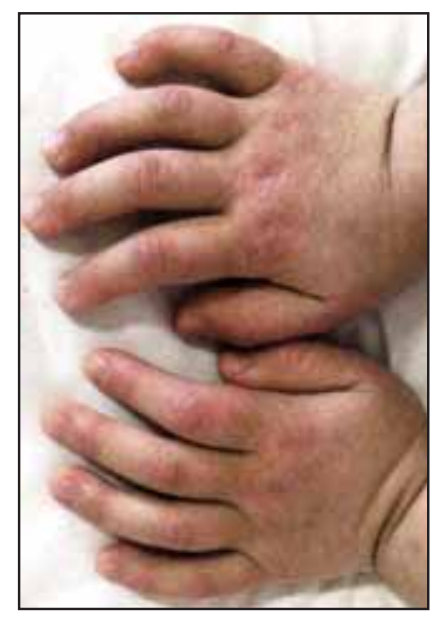

FIGURA 2. Papule Gottron la nivelul MCF, IFP

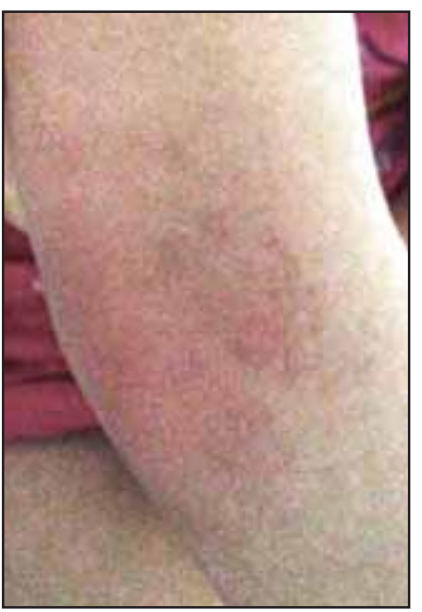

FIGURA 3. Placard eritematos la nivelul cotului

Analizele efectuate au evidențiat anemie hipocromă microcitară, uşoară trombocitopenie, sindrom inflamator biologic absent, transaminaze şi enzime musculare cu valori normale. Capilaroscopia evidențiază anse capilare ramificate (Fig. 5), anse capilare dilatate - unele devenind megacapilare şi scăderea densităţii capilare (Fig. 6). Având în vedere caracteristicile erupției cutanate şi posibilitatea apariției tardive a afectării musculare în DMJ (după luni sau ani), s-a ridicat suspiciunea de derma- 


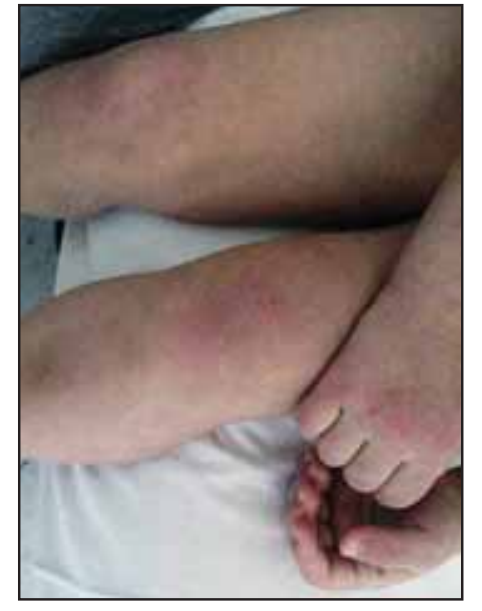

FIGURA 4. Placarde eritematoase la nivelul genunchilor

tomyositis sine myositis (dermatomiozită fară miozită). Profilul de autoanticorpi pentru miozită arată anticorpi anti PL-7 pozitivi (asociaţi cu risc de artrită, fibroză pulmonară interstiţială şi miozită uşoară). Se iniţiază tratament cu Prednison în doză de 5 mg/zi.

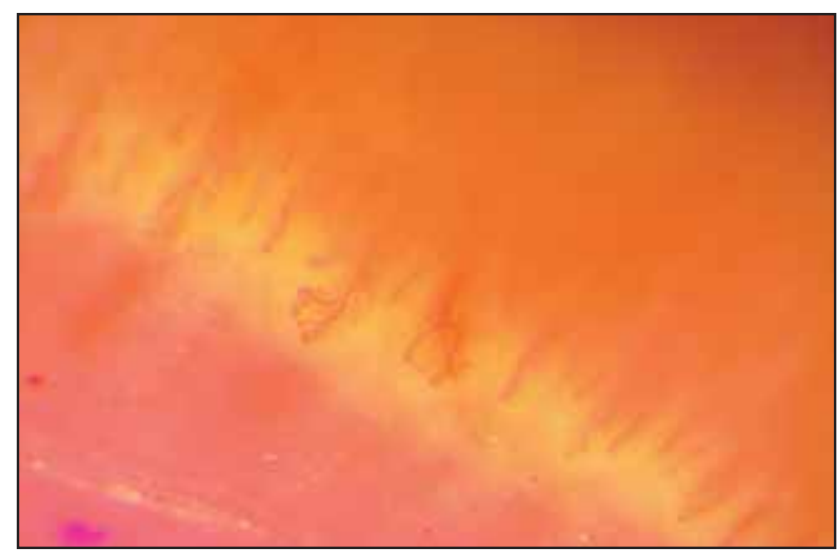

FIGURA 5. Aspect capilaroscopic - scăderea densității capilare, capilare ramificate

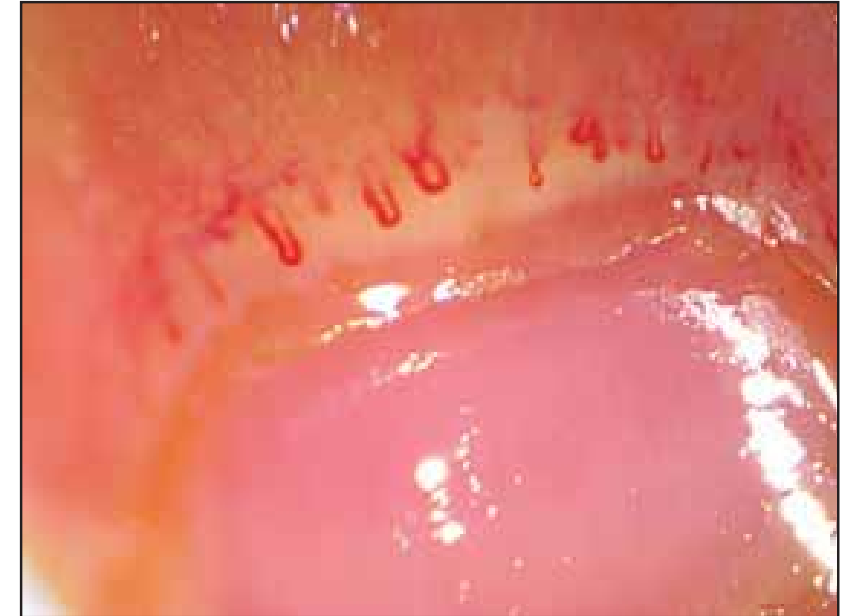

FIGURA 6. Aspect capilaroscopic - scăderea densității capilare, capilare dilatate, megacapilare

Sub acest tratament evoluția a fost favorabilă, cu atenuarea semnelor Gottron şi a faciesului heliotrop, până în mai 2014 când, încă în absența semnelor obiective de afectare musculară, apare citoliză musculară chimică (AST, CK, LDH cu valori crescute), motiv pentru care se decide creşterea dozei de Prednison la $10 \mathrm{mg} / \mathrm{zi}(=0,6 \mathrm{mg} / \mathrm{kg} / \mathrm{zi})$.

După încă 2 luni (iulie 2014) prezintă artrită cu localizări multiple, accentuarea manifestărilor cutanate, cu aspect discret vasculitic (reticular, dar care păleşte la presiune), iar pacienta prezintă slăbiciune musculară. Se menține valoarea crescută a $\mathrm{LDH}$, dar cu valori normale ale CK, AST. Se decide creşterea dozei de PDN la 15 mg/săptămână şi se inițiază tratament cu Metotrexat (MTX) în doză de 5 mg/săptămână, cu evoluție favorabilă, atât în plan

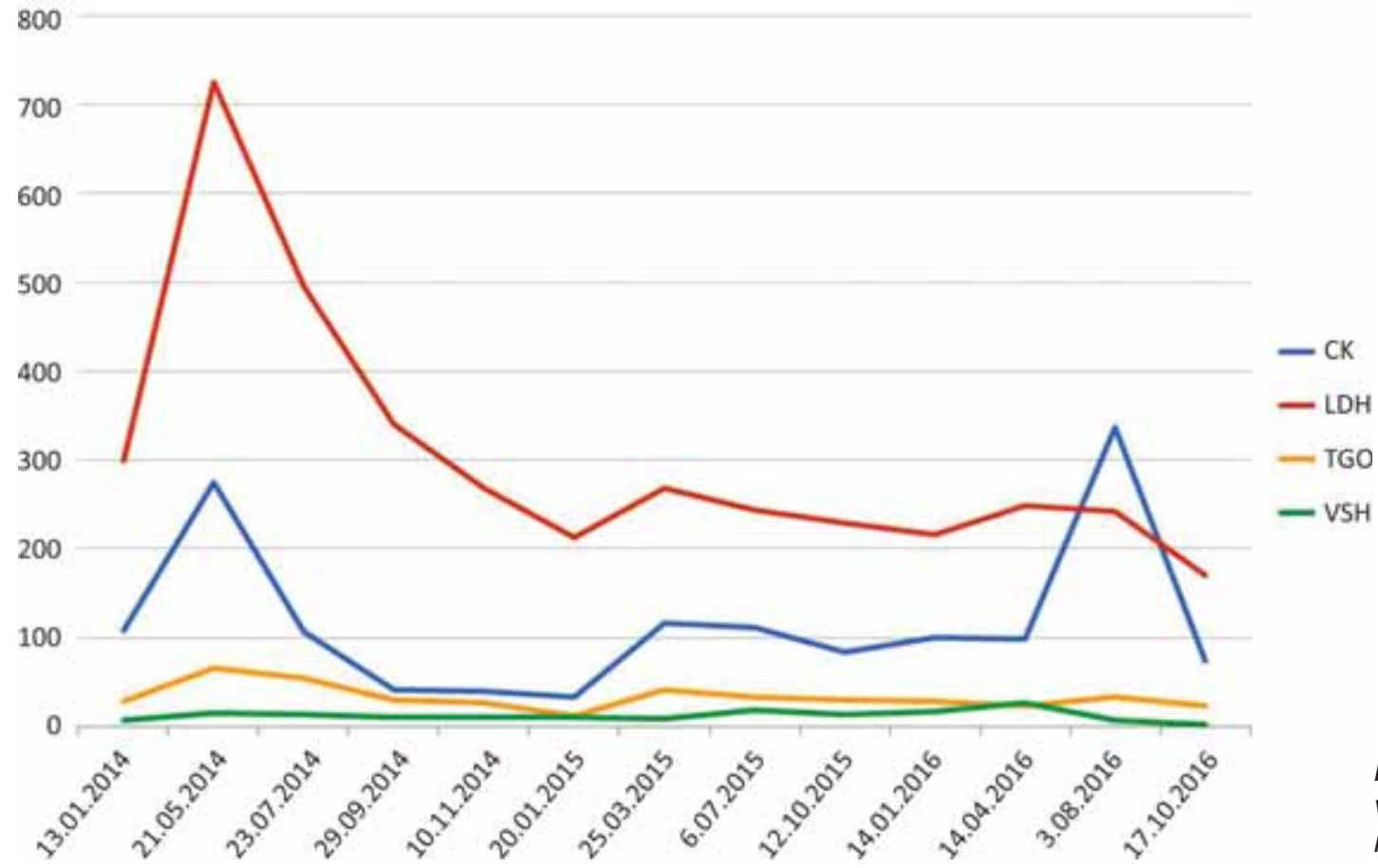

FIGURA 7. Evoluția valorilor enzimelor musculare şi a VSH 
clinic (muscular şi cutanat), cât şi biologic (LDH a continuat să scadă, restul analizelor normale).

Având în vedere doza relativ mare de prednison ( $\sim 0.9 \mathrm{mg} / \mathrm{kgc} / \mathrm{zi})$ cu care s-a obținut această evoluție, doză ale cărei efecte adverse pe termen lung nu sunt acceptabile, s-a decis creşterea în continuare a dozei de metotrexat, în încercarea de a obține controlul adecvat al bolii şi sevrarea de corticosteroid (sistat în mai 2015). În august 2016, fără agravarea semnelor clinice, prezintă din nou citoliză musculară uşoară; pentru a readuce boala sub control se creşte uşor doza de MTX şi se reintroduce o doză mică de prednison. În momentul scrierii articolului boala este controlată atât din punct de vedere clinic (fără erupție; forță musculară normală), cât şi biologic (enzime musculare cu valori normale).

\section{DISCUȚII}

Cazul prezentat subliniază importanța diagnosticului precoce, a monitorizării atente (chiar a cazurilor uşoare, care prezintă doar afectare cutanată) şi a adaptării prompte a tratamentului la nivelul de activitate a bolii (variabil în timp). Îndeplinirea acestor condiții duce la un control adecvat al bolii şi previne apariția complicațiilor ei (atrofii musculare, anchiloze articulare, escare de decubit, calcinoză, pneumonie de aspirație, afectare viscerală, etc.), dar şi pe cele ale tratamentului (sindrom Cushing, diabet, osteoporoză etc.) - determinante ale prognosticului şi absente la cazul prezentat. Se asigură, astfel, o speranță de viață şi o calitate a acesteia apropiate de cele ale populației generale.
Prezența anticorpilor anti PL-7 ar putea explica unele dintre particularitățile acestui caz - miozita uşoară şi cu apariție tardivă, şi asocierea artritei. De asemenea, implicând şi risc pentru fibroză pulmonară interstiţială, este necesară şi monitorizarea pneumologică, subliniind din nou importanța abordării multidisciplinare a acestor cazuri.

Deşi regula generală este să tratăm boli (şi nu rezultate ale unor analize), prezența citolizei musculare chimice (subclinice) trebuie să determine introducerea unui remisiv (metotrexat în cazul prezentat) înaintea apariție semnelor clinice, pentru a preveni pierderea aditivă de masă musculară, precum şi complicațiile bolii.

Deşi absent la cazul prezentat, trebuie subliniat din nou semnul de alarmă reprezentat de apariția disfagiei sau disfoniei.

\section{CONCLUZII}

Diagnosticul precoce, monitorizarea atentă şi adaptarea promptă a tratamentului la nivelul de activitate a DMJ asigură un control adecvat şi previn apariţia complicațiilor bolii, precum şi pe cele iatrogene, oferind o speranţă de viață şi o calitate a acesteia apropiate de cele ale populației generale.

Afectarea cutanată din DMJ poate să o preceadă cu luni sau ani pe cea musculară.

Remisivul poate lipsi din tratamentul formelor uşoare exclusiv cutanate, dar trebuie introdus prompt în momentul apariției altor afectări.

Disfonia şi disfagia sunt factori de alarmă care trebuie să determine începerea unui tratament agresiv (5), dar şi măsuri de protecție a căii aeriene. 